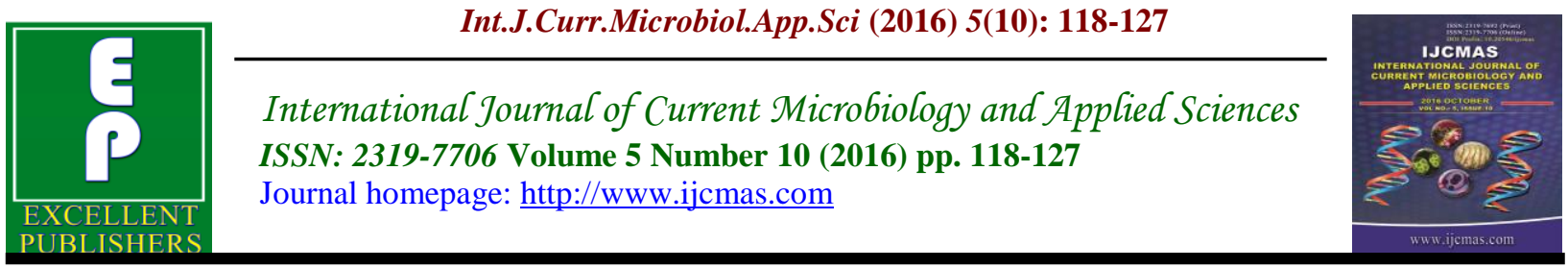

Original Research Article

http://dx.doi.org/10.20546/ijcmas.2016.510.014

\title{
Screening of 1-aminocyclopropane-1-carboxylic acid (ACC) Deaminase Producing Multifunctional Plant Growth Promoting Rhizobacteria from Onion (Allium cepa) Rhizosphere
}

\author{
Niranjan Prakashrao Patil*, Mayuri Inchanalkar, Daisy Desai, \\ Vishal R. Landge and B.D. Bhole \\ Department of Microbiology, Abasaheb Garware College, Pune, Maharashtra, India \\ *Corresponding author
}

\begin{abstract}
A B S T R A C T
Keywords

Allium cepa, Plant Growth Promoting Rhizobacteria, PGPR, ACC deaminase, Multifunctional PGPR, biofertilizer.

\begin{tabular}{l}
\hline Article Info \\
\hline Accepted: \\
12 September 2016 \\
Available Online: \\
10 October 2016
\end{tabular}

The PGP (plant growth promoting) rhizobacteria are root colonizing bacteria which exist in symbiotic relationship with plants. The plant microbe relationship is used to increase crop yield in form of bioinculants applied during cultivation. A study resulted in isolating 61 rhizobacteria from Allium cepa (Onion) root rhizosphere. The screening was carried out to explore multifunctional plant growth promotion traits like Phosphate and Zinc solubilization, Ammonia production, IAA production, HCN production, Siderophore production, and ACC deaminase activity in laboratory condition. The ACC deaminase enzyme activity of bacteria is exploited to relive stress on plants aiming to enhance yield. The multifunctional isolate B10 and V15 revealed maximum 6 out of 7 characters tested. The studies on gnotobiotic seed germination and root elongation assay showed significant increase in treated root length and \% germination compare to equivalent control. The multifunctional PGPR isolates B10 and V15 may show potential as a bioinoculant for increasing crop yields of Onion.
\end{abstract}

\section{Introduction}

By 2020 world's population is predicted to increase from $\sim 7$ billion to $\sim 8$ billion. To feed increasing population, it is necessary to increase agricultural productivity in a sustainable and environmentally friendly approach. Plants are continuously in contact with bacteria throughout their lifetime. Plant growth promoting rhizobacteria (PGPR) affect plant growth directly or indirectly by producing growth substances. It is well established that, in the rhizosphere, only 1-
$2 \%$ of bacteria promote plant growth (Antoun and Kloepper, 2001). The rhizosphere is a hot spot of microbial interactions due to the exudates released by plant roots, which constitute the main food source for microorganisms, leading to efficient geochemical cycling of nutrients. Therefore, screening and selection of effective PGPRs and their utilization in integrated practices is of great importance for enhancing the growth and yield of 
agricultural crops along with maintaining the sustainability of agro-ecosystems (Bakthavatchalu et al., 2012). PGPR are broadly classified into three categories those that colonize the root surface and the close neighborhood (rhizobacteria), those that establish a symbiotic relationship with plants (symbiotic bacteria), and those that can enter into the root interior and colonize inside the plant (endophytic bacteria) (Bacon and Hinton, 2006). PGPR can modulate levels of the plant stress hormone 'ethylene' by producing 1aminocyclopropane-1-carboxylate (ACC) deaminase enzyme by metabolizing ACC into a-ketobutyrate and ammonia (Glick et al., 2007).

While a considerable amount of both basic and applied work remains to be done before ACC deaminase producing plant growth promoting bacteria become a mainstay of plant agriculture, the evidence indicates that with the expected shift from chemicals to soil bacteria, the world is on the verge of a major paradigm shift in plant agriculture (Glick, 2014). Onion is an important vegetable crop more climate sensitive than others. Few studies are aimed at studying rhizobacteria in relation to onion plants (Reetha et al., 2014; Colo et al., 2014; Reddy et al., 1989). This research work aims at isolating multifunctional PGPR's of Onion rhizosphere showing growth promotion. The isolated PGPR's should exhibit ACC deaminase activity in addition to other traits.

\section{Materials and methods}

\section{Chemicals and reagents}

Aminocyclopropane-1-carboxylic acid, $\alpha$ ketobutyrate, 2,4, Dinitro phenylhydrazine were purchased from Merk India Pvt.Ltd. Chrome azurol $\mathrm{S}$ reagent, microbiological media and media components were purchased from HiMedia India Pvt. Ltd. All the other chemicals purchased were reagent grade.

\section{Sampling and Isolation of rhizobacteria}

The Onion plant samples were collected (different growth stages) from diverse locations of Nashik District (Maharashtra, India) in sterile plastic bags. The samples were kept on ice bags during transport, and processed after refrigeration in laboratory. The roots of the plants were cut and washed gently with sterile distilled water to remove excessive adherent soil. The root samples were serially washed and vigorously vortex with sterile saline and aliquot of washed water was used to isolate bacteria using Streak plate and spread method on Nutrient agar and Soil extract Agar. The isolated colonies that developed on the plates were sub-cultured repeatedly to acquire pure single colony, which was preserved on agar slants for further characterization and identification .The pure cultures were preserved on nutrient agar slants. The Onion (Allium cepa) seeds were purchased from local market.

\section{Screening of PGPR traits}

The isolates were evaluated for following plant growth promoting traits.

\section{Indole acetic acid production}

The bacterial capacity to produce Indole acetic acid (IAA) was detected as described by Brick et al., (1991). 1\% tryptone water broth was inoculated with loop full of bacterial suspension and incubated for 48 hours at $30 \pm 2^{\circ} \mathrm{C}$. The broth was centrifuged at $10000 \mathrm{rpm}$ for $10 \mathrm{~min}$ and two drops of orthophosphoric acid were added to $2 \mathrm{ml}$ of cell free supernatant and the development of color was observed. After for 30 min in dark development of pink colour indicates IAA production. 


\section{Siderophore production test}

The culture was tested for siderophore production by using Chrome-azurol S (CAS) medium which was described by Schwyn and Neilands (1987). The $24 \mathrm{~h}$ old cultures were spot inoculated on CAS medium and incubated at room temperature for 72 hours. Siderophore producing cultures were identified by formation of clear zone around the colonies.

\section{Ammonia production test}

The ammonia production was detected by Cappuccino and Sherman (1992) method using Nessler's reagent. Overnight grown bacterial cultures were inoculated in $3 \mathrm{ml}$ $1 \%$ peptone broth and incubated at room temperature for $24 \mathrm{hrs}$ on Shaker at 120 RPM. $0.5 \mathrm{ml}$ of Nessler's reagent was added to the grown broth after incubation. The development of faint yellow to dark brown color indicated the production of ammonia.

\section{Phosphate solubilization test}

The phosphate solubilization test was performed on Pikovaskay's agar plates as described by Pikovaskay (1948). The 24 hour old cultures were spot inoculated on these plates and incubated for 72 hours at room temperature. Phosphate solubilization was detected by clear zone around the colonies.

\section{Zinc solubilization}

The isolates were spot inoculated on medium containing $0.1 \%$ Zinc oxide (Goteti et al., 2013). After the two days incubation Clear zone around the bacterial colony indicates zinc solubilizing ability of bacteria.

\section{HCN production}

The $\mathrm{HCN}$ production ability of isolates was determined using modified method of
Castric (1975). The screw capped tubes Nutrient agar containing glycine $(4.4 \mathrm{~g} / \mathrm{L})$ slant was streaked with isolates. A Whatman Filter paper no. 1 strip soaked in $2 \%$ Sodium carbonate in $0.5 \%$ picric acid was placed on the top of the tube and was tightly capped. Tubes were incubated for 48 hours $30 \pm 2^{\circ} \mathrm{C}$. Development of orange to red color on paper indicates $\mathrm{HCN}$ production.

\section{ACC Deaminase production}

ACC-deaminase activity of rhizobacteria was determined qualitatively by using yeast carbon base medium containing ACC as sole nitrogen source. Qualitative detection of ACC-deaminase activity of rhizobacteria was carried out according to modified methods of Honma and Shimomura (1978) and Penrose and Glick (2003). This method detects the amount of $\alpha$ - ketobutyrate produced when the enzyme ACC deaminase cleaves ACC. $0.3 \mathrm{M}$ ACC stock was prepared by membrane $(0.45 \mu)$ filter sterilization and stored at $-20^{\circ} \mathrm{C}$.

\section{Characterization of isolates}

The taxonomic attributes of selected isolates were determined using routine morphological (colonial, Gram staining and motility) and biochemical (catalase, oxidase, amylase and gelatinase) criteria.

\section{Gnotobiotic root elonagation assay}

The gnotobiotic root elongation assay is used as a method of assessing the effect of various bacterial strains on the growth of Onion seedlings. The three cultures (B10, V15 and were selected and assay was performed in triplicates.

\section{Preparation of inoculum}

The selected PGPR cultures were inoculated in sterile nutrient broth and incubated at 
room temperature for $24 \mathrm{~h}$ under shaking (120 rpm) conditions. The cells were centrifuged to obtained pellet and pellet was re-suspended in saline. The washing of pellet was repeated two times. Finally, an Optical density of 0.5 at $600 \mathrm{~nm}$ was adjusted in saline and used for seed inoculation.

\section{Seed surface sterilization}

Uniform sized seeds were selected for assay. 30 seed were used per culture per plate. The onion seeds were surface sterilized by dipping in $95 \%$ ethanol solution for $2 \mathrm{~min}$, $0.2 \% \mathrm{HgCl} 2$ solution for $3 \mathrm{~min}$ and washed thoroughly with distilled water for 6 times.

\section{Seed inoculation}

Surface sterilized onion seeds were taken into another sterile Petri-plate and soaked in to inoculum for $30 \mathrm{mins}$. The seeds were shaken well so that fine coating will appear on the seeds. The equivalent distilled water treatment served as negative treatment. The seeds were placed equidistant on moist sterile filter paper sheets in petri plates. The plates were incubated at room temperature and left undisturbed. Plates were observed on daily basis and after $24 \mathrm{hrs} 10 \mathrm{ml}$ sterile distilled water was replenished.

\section{Statistical analysis}

The root and shoot lengths were measured to the nearest of millimeter and statistical analysis of data was done. The data were statistically tested by one way analysis of variance (ANOVA) and means were separated by Tukey Kramer HSD Post-hoc test using Minitab 14 software. Each treatment was analyzed with at least three replicates and a standard deviation (SD) was calculated and data are expressed in mean \pm SD. The observations were considered significant when $\mathrm{P}$ was $\leq 0.05$.

\section{Results and Discussion}

\section{Isolation of rhizobacteria and Characterization of isolate}

Ten diverse onion fields were selected for isolation of PGPR from rhizosphere. The outcome of isolation experiment was 61 bacterial isolate in pure culture. The isolates were qualitatively evaluated for 7 different Plant growth promotion traits. The selected six isolate also showed variation in morphological characters, biochemical characters and colony morphology. The goal of determining taxonomic character was to ensure that isolates of different types are studied (Table 2). Nonetheless, the identification of isolates up to species level will be followed depending on its potential in promoting growth and productivity. Reetha et al., (2014) isolated indole acetic acid producing rhizobacteria Pseudomonas fluorescence and Bacillus subtilis from Onion rhizosphere enhancing its growth. Our approach of isolating and utilizing multifunctional PGP rhizobacteria for increasing crop yield is more lucrative for success of treatment. The dynamic soil and varied climatic conditions affect crop yield the most. To address the varied needs of plant growth isolate possessing multiple activities may prove more successful In vivo. According to Martínez-Viveros et al., (2010) the PGPR often have more than one mechanism for enhancing plant growth and experimental evidence suggests that the plant growth stimulation is the net result of multiple mechanisms of action that may be activated simultaneously.

\section{PGPR characters}

The best six isolates exhibiting minimum 4 and maximum 6 traits out of 7 traits studied are shown in Table 1. The isolates with maximum number of PGPR traits were 
selected for further studies 5 isolates were exhibiting IAA production character out of 6 selected. Loper and Schorth (1986) reported that $80 \%$ of bacteria isolated from rhizosphere exhibit IAA production character. Zinc $(\mathrm{Zn})$ deficiency is a global nutritional problem in crops grown in calcareous soils that is important for the development and function of growth regulators (e.g. auxin) and chloroplast. Zinc deficient plants are stunted and have twisted, outward bending leaves affecting yield of crop (Rafique et al., 2008). All the isolate selected have zinc solubilization activity useful when zinc is not available in utilizable form. Figure 1 shows zone of clearance around isolate B10 and V15 colony revealing $\mathrm{Zn}$ solubilization. Phosphorus is important plant nutrient affecting overall plant growth and crop yield.

Table.1 Multiple PGPR traits of strains isolated from rhizosphere of Allium cepa

\begin{tabular}{|c|c|c|c|c|c|c|c|}
\hline \multirow{2}{*}{$\begin{array}{l}\text { Isolate } \\
\text { Code }\end{array}$} & \multirow{2}{*}{$\begin{array}{l}\text { ACC } \\
\text { deaminase }\end{array}$} & \multirow{2}{*}{$\begin{array}{l}\text { IAA } \\
\text { production }\end{array}$} & \multirow{2}{*}{$\begin{array}{l}\text { Siderophore } \\
\text { production }\end{array}$} & \multirow{2}{*}{$\begin{array}{l}\text { Ammonia } \\
\text { Production }\end{array}$} & \multirow{2}{*}{$\begin{array}{l}\text { HCN } \\
\text { production }\end{array}$} & \multicolumn{2}{|c|}{ Solubilization } \\
\hline & & & & & & Zinc & Phosphate \\
\hline NF5 & - & + & - & + & - & + & + \\
\hline NOR3 & - & - & + & + & + & + & + \\
\hline K3 & - & + & + & + & - & + & + \\
\hline B10 & + & + & + & + & - & + & + \\
\hline V15 & + & + & - & + & + & + & + \\
\hline T36 & - & + & + & + & - & + & - \\
\hline
\end{tabular}

$+=$ detected, - = not detected

Table.2 Characterization of selected strains isolated from rhizosphere of Allium cepa.

\begin{tabular}{|l|l|l|l|l|l|l|l|}
\hline $\begin{array}{l}\text { Tsests } \\
\text { Isolate codes }\end{array}$ & $\begin{array}{l}\text { Gram } \\
\text { character }\end{array}$ & Shape & Motility & Catalase & Oxidase & Amylase & Gelatinase \\
\hline NF5 & Positive & Cocci & - & + & - & - & - \\
\hline NOR3 & Negative & Rods & + & + & - & + & - \\
\hline K3 & Positive & Cocci & - & + & + & - & + \\
\hline B10 & Positive & Rods & + & + & - & - & - \\
\hline V15 & Positive & Rods & + & + & - & + & - \\
\hline T36 & Negative & Rods & - & + & + & - & + \\
\hline
\end{tabular}

$+=$ detected, - = not detected

Table.3 Seed growth promotion of Allium cepa seeds by Isolate B10, V15 and K3 compare to control

\begin{tabular}{|l|l|l|l|l|}
\hline \multicolumn{1}{|c|}{ Treatment } & Control & B10 & V15 & K3 \\
Parameters & & & & \\
\hline Germination rate (\%) & 73 & 86 & 83 & 80 \\
\hline Root length(cm) & $2.49 \pm 0.67$ & $3.87 \pm 1.59^{* *}$ & $3.15 \pm 1.24^{*}$ & $3.19 \pm 1.58^{\mathrm{NS}}$ \\
\hline
\end{tabular}

Values are mean of three experiments $\pm \mathrm{SD}$, significantly different from the control at $* * \mathrm{P}<0.001$, $* \mathrm{P}<0.05,{ }^{\mathrm{NS}}=$ not significant by one way analysis of variance (ANOVA) with Tukey Kramer HSD Posthoc test 
Fig.1 Clear zone around isolate B10 and V15 colony showing Zn solubilization

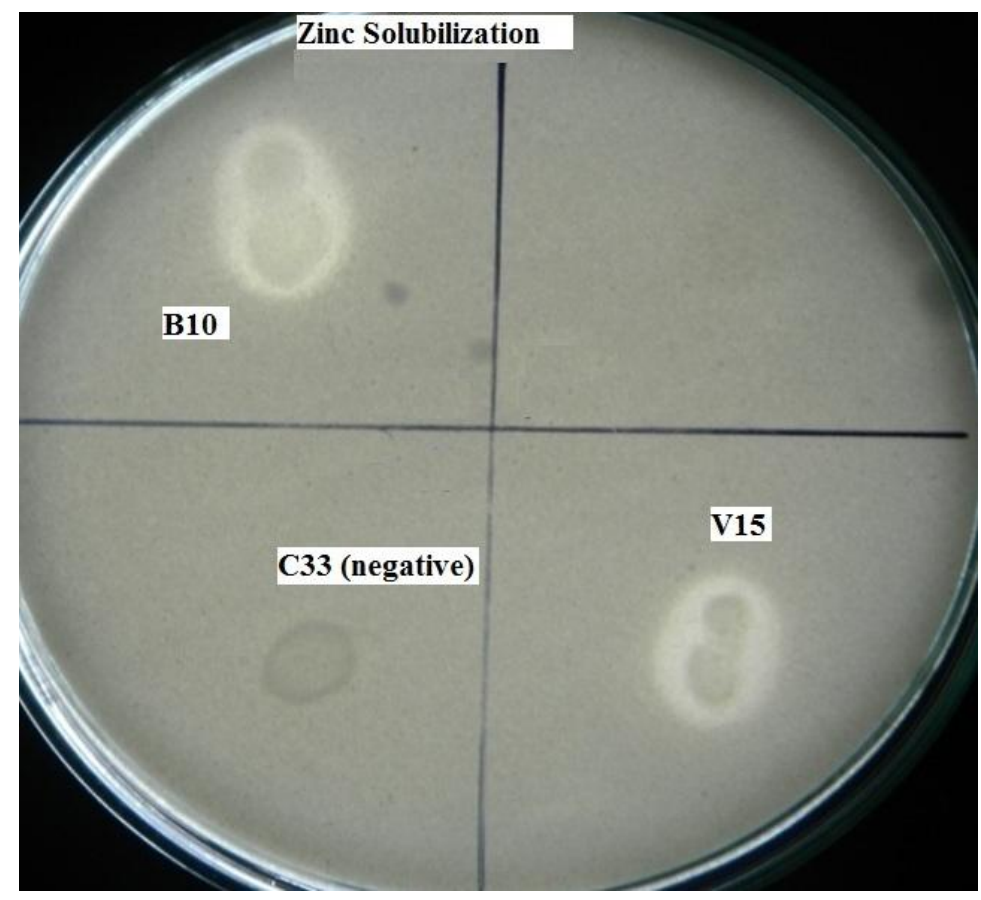

Fig.2 Clear zone around isolate B10 showing phosphate solubilization

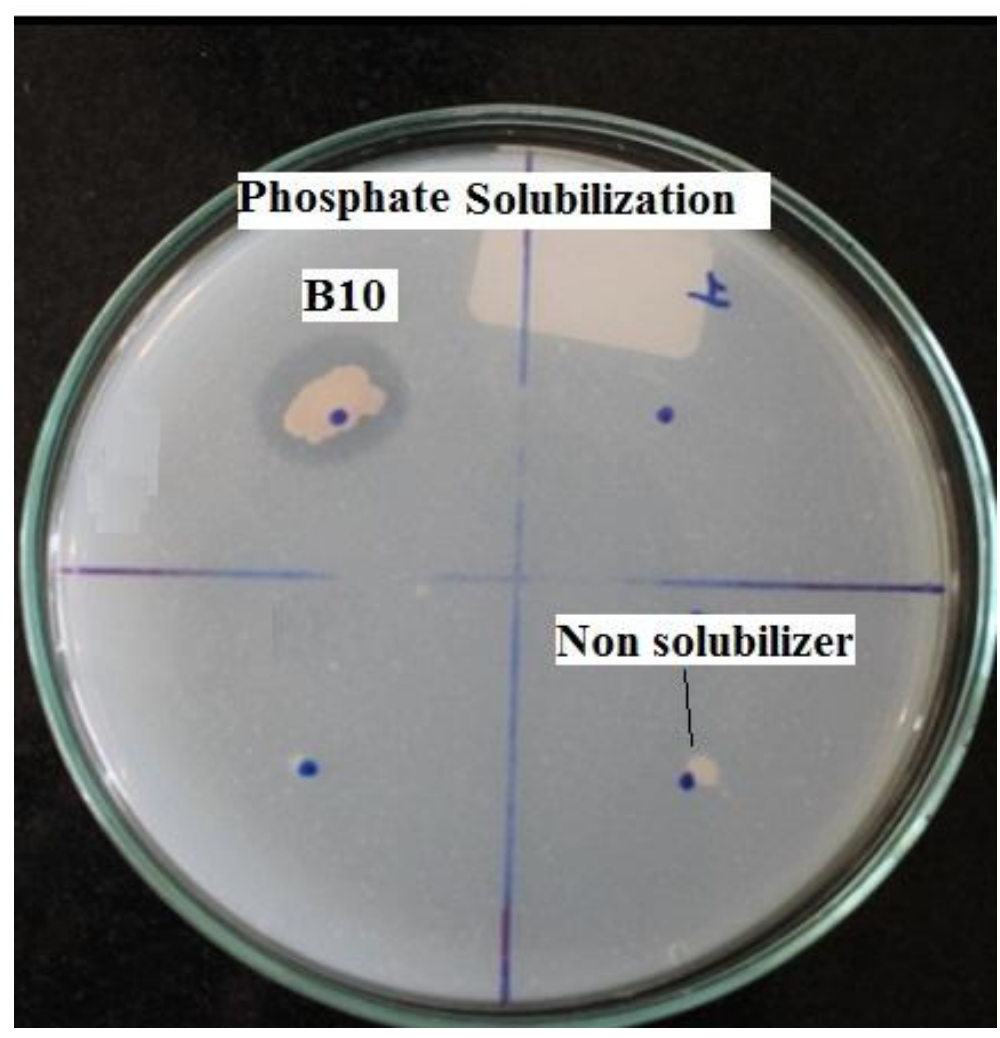


Fig.3 Production of HCN by Isolate V15

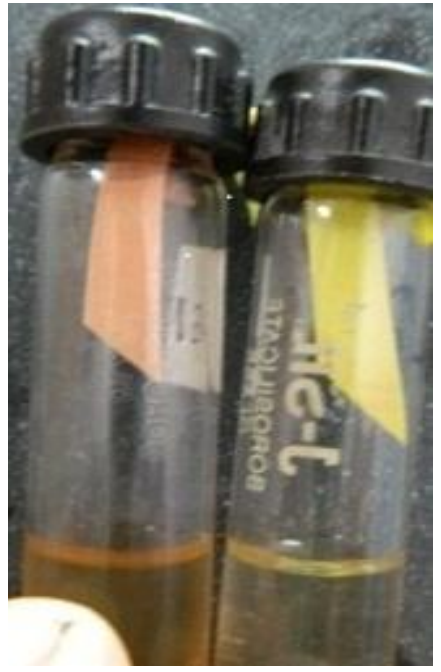

Fig.4 Production of ACC deaminase by Isolate V15

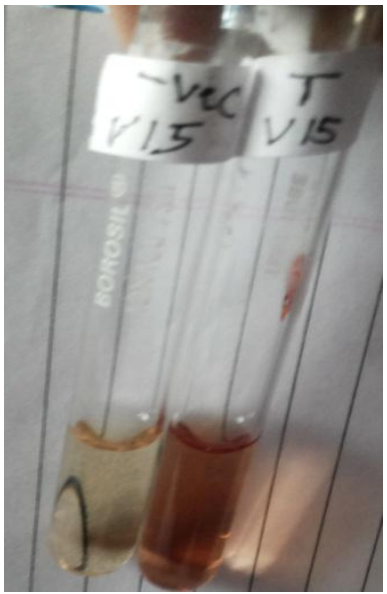

Fig.5 Allium cepa seed germination root elongation with respect to treated(B10) and control

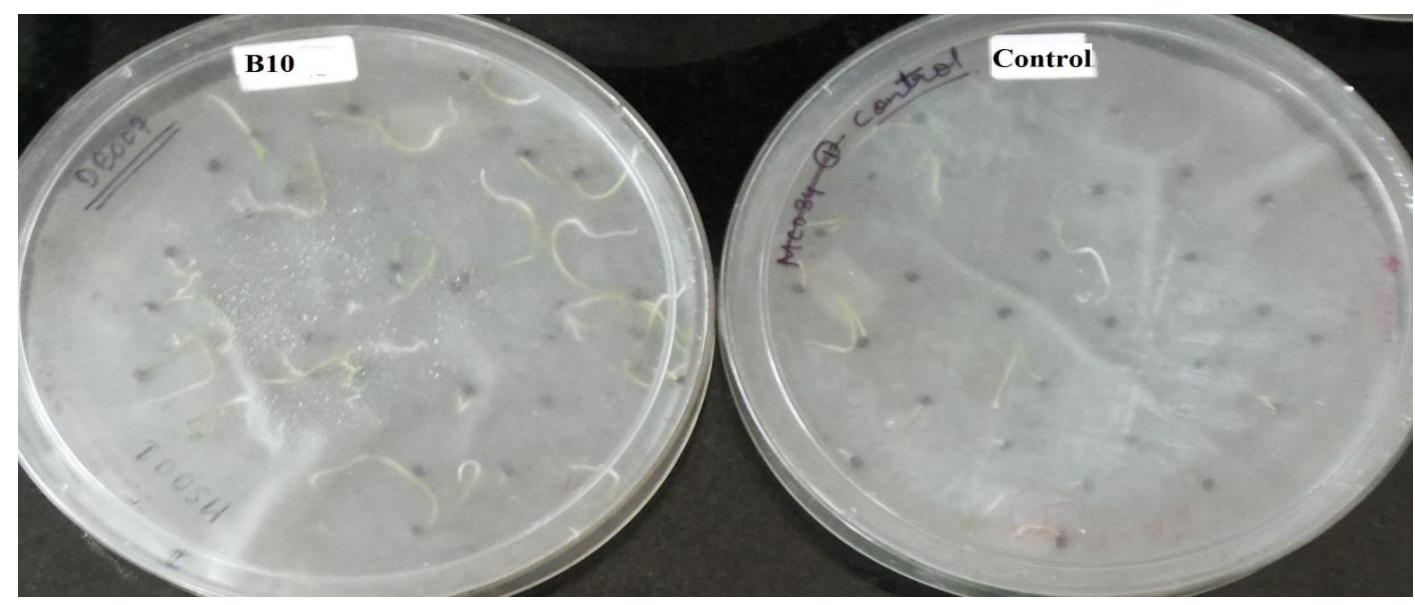


In our study five isolates were exhibiting phosphate solubilization activity out of six selected. PGPR transform inaccessible compounds into forms accessible to plants by production of organic acid and phosphatase enzyme (Khan et al., 2014). Figure 2 shows zone of clearance around isolate B10 colony indicating phosphate solubilization. Siderophores are high affinity $\mathrm{Fe}^{3+}$ chelating compounds produced by microbes which take $\mathrm{Fe}^{3+}$ out of its compounds, bind it and form a $\mathrm{Fe}^{3+}$ siderophore complex, when accessible iron is lacking. $\mathrm{Fe}^{3+}$-siderophore complex is transported to the surface of a bacterial cell or root cells, transported into the cell and reduced to $\mathrm{Fe}^{+2}$. Plants are capable of binding the bacterial $\mathrm{Fe}^{3+}$ siderophore complex, thus PGPR help in providing the plant with iron (Colo et al., 2014). In our work, four siderophore producing strains were isolated and selected for further study.

The bacterial production of $\mathrm{HCN}$ has been reported as an important antifungal trait to control root infecting fungi and inducer of plant resistance. Figure 3 show representative production of $\mathrm{HCN}$ by Isolate B10.Ammonia production was detected in $95 \%$ of the bacteria isolated from rhizosphere of rice, mangroves and soils contaminated by effluent (Noumavo et al., 2015). All the selected isolates were $\mathrm{NH}_{3}$ positive.

The ethylene is considered as a stress hormone, whose synthesis in plants is increased in harsh biotic and abiotic stresses. The higher levels of ethylene inhibit growth and development of plants (Glick et al., 2007). The enzyme ACC deaminase lowers level of ethylene by competing with enzyme ACC oxidase. The presence of ACC deaminase activity in rhizobacteria may relieve plant from stress in effect increasing crop yield. We found two isolate (B10 and
V15) producing ACC deaminase enzyme. Figure 4 shows production of ACC deaminase by Isolate V15.

\section{Gonotobiotic root elongation assay}

The isolates B10, V15 and K3 were chosen to assess their effect on germination and root elongation in gnotobiotic condition. The B10, V15 and K3 treated seeds showed $86 \%, 83 \%$, $80 \%$ germination respectively, significantly higher than control treatment $73 \%$ (Figure 5 and Table 3). The root lengths of isolate B10 and V15 were significantly higher than control, but significant difference was not observed between root length of $\mathrm{K} 3$ treatment and control. The shoot development was not observed in six days of incubation. ACC deaminase production may play significant role in germination and root elongation of onion seeds. Similar studies by Noumavo et al., (2013) reported the promoter effect of rhizobacteria (A. lipoferum, P. fluorescens, $P$. putida) on germination and the plants growth of maize in plate assay. Li et al., (2000) reported that mutant of the ACC deaminase gene from Enterobacter cloacae UW4 diminished the ability of the bacterium to promote the elongation of canola roots under gnotobiotic conditions.

In conclusion, ACC deaminase activity was detected in two isolates from onion rhizosphere coded as B10 and V15. The various multifunctional PGPR activities exhibited were IAA, ammonia, siderophore, HCN production and Zinc and phosphate solubilization by isolates. The isolate B10 and V15 significantly increased germination and root elongation compare to equivalent control in gnotobiotic assay. Therefore, it may be advantageous to use plant growth promoting rhizobacteria as a means to promote plant growth and increase crop yield by lowering ethylene levels rather than 
relying on genetically modified plants or chemical fertilizer.

\section{Acknowledgments}

The author gratefully acknowledges financial support provided by University Grant Commision (UGC) of India via grant number 47-509/12 (WRO) for minor research project.

\section{References}

Antoun, H., and Kloepper, J.W. 2001. Plant growth promoting rhizobacteria. In: Encyclopedia of Genetics(Eds.) S. Brenner and J.Miller. Academic, New York. pp. 1477-1480.

Bacon, C.W., and Hinton, D.M. 2006. Bacterial endophytes: the endophytic niche, its occupants, and its utility. In: Plant-associated bacteria(Eds.) S. Gnanamanickam. Springer, The Netherlands, pp 155-194.

Bakthavatchalu, S., S. Shivakumar, and Sullia, S. 2012. Identification of multitrait PGPR isolates and evaluation of their potential as biocontrol agents. Acta Biologica Indica, 1(1): 61-67.

Brick, J.M., R.M. Bostock, and Silverstone, S. E. 1991. Rapid in-situ assay for indole acetic acid production by bacteria immobilized on nitrocellulose membrane. Appl. Environ. Microbiol., 57: 535-538.

Cappuccino, J.G., and Sherman N. 1992. Biochemical activities of microorganisms. In: Microbiology, A Laboratory Manual. The Benjamin / Cummings Publishing Co.California, USA.

Castric, P.A. 1975. Hydrogen cyanide, a secondary metabolite of Psuedomonas aeruginosa. Can. J. Microbiol., 21: 613-618.

Colo, J., J.T. Hajnal, S. Duric, D. Stamenov, and Hamidovic, S. 2014 Plant growth promotion rhizobacteria in onion production. Pol. J. Microbiol., 63(1): 83-8.

Glick, B.R. 2014. Bacteria with ACC deaminase can promote plant growth and help to feed the world. Microbiol. Res., 169(1): 30-39.

Glick, B.R., B. Todorovic, J. Czarny, Z.Cheng, J. Duan, and McConkey, B. 2007. Promotion of plant growth by bacterial ACC deaminase. Crit. Rev. Plant Sci., 26: 227-242.

Goteti, P.K., L.D.A. Emmanuel, S. Desai, and Shaik, M.H.A. 2013. Prospective Zinc Solubilising Bacteria for Enhanced Nutrient Uptake and Growth Promotion in Maize (Zea mays L.). Int. J. Microbiol., 869697 10.1155/2013/869697.

Honma, M, and Shimomura T. 1978. Metabolism of 1-aminocyclopropane1-carboxylic acid. Agri. Biol. Chem., 42: 1825-1831.

Khan, M., S.A. Zaidi, and Ahmad, E. 2014. Mechanism of phosphate solubilization and physiological functions of phosphate solubilizing microorganisms. In: Phosphate Solubilizing Microorganisms Principles and Application of Microphos Technology (Eds.) M.S. Khan Springer publishers Switzerland.Pp.31-62.

Li, J., Daniel, H., Ovakim, Trevor, C., Charles, Bernard, R., Glick. 2000. An ACC Deaminase Minus Mutant of Enterobacter cloacae UW4 No Longer Promotes Root Elongation Curr. Microbiol., 41: 101-105.

Loper, J.E., and Schroth, M.N. 1986. Influence of bacterial sources of indole-3-acetic acid on root elongation of sugarbeet. Phytopathol., 76: 386389.

Martínez-Viveros, O., M.A. Jorquera, D.E., 
Crowley, G., Gajardo, and Mora, M.L. 2010. Mechanisms and practical considerations involved in plant growth promotion by rhizobacteria. $J$. Soil Sci. Plant Nutri., 10(3): 293-319. Noumavo, P.A., E. Kochoni, Y.O. Didagbe, A. Adjanohoun, M. Allagbe, R. Sikirou, and Gachomo, E.W. 2013. Effect of different plant growth promoting rhizobacteria on Maize seed germination and seedling development. American J. Plant Sci., 4(5): 1013-1021.

Noumavo, P.A., N.A. Agbodjato, and Gahomo, E.W., et al. 2015. Metabolic and biofungicidal properties of maize rhizobacteria for growth promotion and plant disease resistance. African $J$. Biotechnol., 14(9): 811-819.

Penrose, D.M., and Glick, B.R. 2003. Methods for isolating and characterizing ACC deaminase containing plant growth-promoting rhizobacteria. Physiologia Plantarum, 118: 10-15.

Pikovskaya, R.I. 1948. Mobilization of phosphorus and soil in connection with the vital activity of some microbial species. Microbiol., 17: 362-70.

Rafique, E., M. Mahmood-ul-Hassan, K.M. Khokhar, G. Nabi and Tabassam, T. 2008. Zinc Nutrition of Onion: Proposed Diagnostic Criteria. J. Plant Nutri., 31(2): 307-316.

Reddy, M.S., and Rahe, J. 1989 Bacillus subtilis B-2 and selected onion rhizobacteria in onion seedling rhizospheres: effects on seedling growth and indigenous rhizosphere microflora. Soil Biol. Biochem., 21(3): 379-383.

Reetha, S., G., Bhuvaneswari, P., Thamizhiniyan, and RaviMycin, $\mathrm{T}$. 2014. Isolation of indole acetic acid (IAA) producing rhizobacteria of Pseudomonas fluorescens and Bacillus subtilis and enhance growth of onion (Allim cepa.L) Int. J. Curr. Microbiol. App. Sci., 3(2): 568-574.

Schwyn, B., and Neilands, J. 1987. Universal chemical assay for the detection and determination of siderophores. Anal. Biochem., 160: 4756.

\section{How to cite this article:}

Niranjan Prakashrao Patil, Mayuri Inchanalkar, Daisy Desai, Vishal R. Landge and B.D. Bhole. 2016. Screening of 1-aminocyclopropane-1-carboxylic acid (ACC) Deaminase Producing Multifunctional Plant Growth Promoting Rhizobacteria from Onion (Allium cepa) Rhizosphere. Int.J.Curr.Microbiol.App.Sci. 5(10): 118-127. doi: http://dx.doi.org/10.20546/ijcmas.2016.510.014 